\title{
Determination of chlorinated solvents in industrial water and wastewater by DAI-GC-ECD
}

\author{
Marek Tobiszewski • Jacek Namieśnik
}

Received: 15 October 2010 /Revised: 7 January 2011 / Accepted: 10 January 2011 /Published online: 29 January 2011

(C) The Author(s) 2011. This article is published with open access at Springerlink.com

\begin{abstract}
A very simple and quick analytical method, based on direct aqueous injection, for determination of halogenated solvents in refinery water and wastewater, is described. There is a need to determine halogenated solvents in refinery water streams, because they may originate from several processes. There is also a need to develop methods enabling VOX to be determined in samples containing oil fractions. The method described enables simultaneous determination of 26 compounds with low detection limits $\left(\right.$ sub- $\left.\mu \mathrm{g} \mathrm{L}^{-1}\right)$ and excellent precision, especially for highly halogenated solvents. The matrix effects of four types of sample were evaluated - the method seemed to be relatively insensitive to variations in matrix composition. Deuterated 1,2-dichloroethane was used as internal standard and surrogate compound in quantitative analysis; application of isotopically labelled compounds is rarely reported when non-mass spectrometric detectors are used for analysis. Analysis of real samples showed that the most frequently detected compounds were dichloromethane and 1,2-dichloroethane.
\end{abstract}

Keywords Gas chromatography · Trihalomethanes · Matrix effects $\cdot$ VOX $\cdot$ Isotopically labelled compounds

\section{Introduction}

Halogenated solvents are compounds of great environmental concern because they can contaminate surface and ground waters. They are volatile and can therefore be easily transferred

\footnotetext{
M. Tobiszewski $(\square) \cdot J$. Namieśnik

Department of Analytical Chemistry, Chemical Faculty,

Gdańsk University of Technology (GUT),

ul. G. Narutowicza 11/12,

80-233 Gdańsk, Poland

e-mail: marektobiszewski@wp.pl
}

to the air and transported in the atmosphere [1]. Halogenated solvents present in water may undergo a series of dehalogenation reactions leading to the formation of more toxic daughter compounds [2]. The presence in water of both parent and daughter halogenated compounds constitutes a risk to aquatic ecosystems and human health. The quality of industrial water can be assessed by measuring total organic carbon, biological or chemical oxygen demand, total petroleum hydrocarbons, and oil and grease [3]. However, chlorinated solvents also affect the quality of water. At high temperatures they can undergo mineralization resulting in chloride formation, which can cause corrosion. They can be present in refinery water as a result of the chlorination of water, with trihalomethanes (THMs) the main by-products of disinfection [4]. Chlorination is used to prevent biological fouling of facilities in which water is used as a cooling agent. During chlorination in the presence of humic matter and chlorides or bromides, chloroform, bromodichloromethane, dibromochloromethane, and bromoform are formed [5]. 1,2-Dichloroethane and dichloromethane are used as solvents in the Di-Me (dichloroethane-methylene dichloride) wax de-oiling process. At low temperatures crystallized wax is separated from oil in Di-Me solution. Historically, 1,2-dichloroethane and 1,2-dibromoethane used to be added to leaded petrol as lead scavengers to prevent the lead fouling of engines [6]. Lead scavengers during combustion form volatile lead halides, which are removed in the exhaust. Trichloroethene and tetrachloroethene and other halogenated solvents are used as metal surface degreasing agents [7].

Combinations of direct aqueous injection (DAI) with electron-capture detection [8], flame-ionisation detection, and mass spectrometry [9-11] have been reported. DAI has significant advantages. No analyte isolation or enrichment is needed, so the risk of analyte loss or sample contamination during sample preparation is minimised. As hardly any 
solvents are used in the procedure, the technique complies with the concept of green analytical chemistry [12]. Oncolumn injectors and cooling systems are used to prevent sample volatilisation before injection on to the column, and deactivated guard columns are used to prevent deterioration of the inlet of the capillary column by inorganic salts or nonvolatile organic compounds. Generally, injection of water into the GC column does not prevent column deterioration; thick, nonpolar stationary phases are used. Another guard column is placed between the column and the detector, which operates at a high temperature: a direct columndetector connection would result in excessive column bleed.

DAI-GC-ECD is considered to be applicable to samples with clean matrices only (no suspended matter present in the sample). The technique has been used for determination of trihalomethanes in groundwater and tap water [5], chlorinated volatile and semivolatile compounds in surface water [13], and halogenated solvents in rainwater [14]. With some modifications of the mode of injection, it has also been used for analysis of chemical production wastewater at $\mathrm{mg} \mathrm{L}^{-1}$ levels [15].

The objective of this study was to develop quick and reliable chromatographic techniques for determining halogenated solvents in water streams at a crude oil refinery. Metrological data for the method are described and compared with those of other analytical techniques widely used to determine chlorinated solvents. Analysis of oil-contaminated wastewater samples is difficult, so the development of a rapid analytical method is desirable. There is little information in the literature about the determination of halogenated compounds in samples containing oil fractions.

\section{Materials and methods}

\section{Materials}

Standards were obtained as a mixture of allyl chloride, bromodichloromethane, bromoform, bromomethane, carbon tetrachloride, chlorobenzene, chloroethane, chloroform, chloromethane, dibromochloromethane, 1,2-dibromo-3chloropropane, 1,2-dibromoethane, dibromomethane, 1,2dichlorobenzene, 1,3-dichlorobenzene, 1,4-dichlorobenzene, trans-1,4-dichloro-2-butene, dichlorodifluoromethane, 1,1dichloroethane, 1,2-dichloroethane, 1,1-dichloroethene, trans-1,2-dichloroethene, 1,2-dichloropropane, cis-1,3dichloropropene, trans-1,3-dichloropropene, methyl iodide, dichloromethane, 1,1,1,2-tetrachloroethane, 1,1,2,2-tetrachloroethane, tetrachloroethene, 1,1,1-trichloroethane, 1,1,2tetrachloroethane, trichloroethene, trichlorofluoromethane, 1,2,3-trichloropropane, vinyl chloride (100 $\mu \mathrm{g} \mathrm{mL}^{-1}$ of each) in methanol (Ultra Scientific, USA). 1,2-Dichloroethane-d $\mathrm{d}_{4}$
(2000 $\mu \mathrm{g} \mathrm{mL}^{-1}$ in methanol; internal standard (I.S.) and surrogate compound) was purchased from Supelco, USA. Standard solutions were prepared by diluting stock solutions with ultrapure water (Milli-Q Millipore system, France).

\section{Apparatus}

The GC 8000Top gas chromatograph (Carlo Erba Instruments, Italy) was equipped with a cold "on-column" injector with secondary cooling, $60 \mathrm{~m} \times 0.32 \mathrm{~mm}$ i.d., $1.8 \mu \mathrm{m}$ film thickness Zb-624 column (Zebron, USA), guard column, and ECD 850 electron-capture detector (Carlo Erba Instruments, Italy).

\section{Chromatographic conditions}

The temperature programme was started at $102^{\circ} \mathrm{C}$ and held for $7 \mathrm{~min}$, after which it was raised to $110^{\circ} \mathrm{C}$ at $2^{\circ} \mathrm{min}^{-1}$, and then to $200{ }^{\circ} \mathrm{C}$ at $10^{\circ} \mathrm{min}^{-1}$, where it was held for $5 \mathrm{~min}$. Hydrogen was the carrier gas, at a flow rate of $2.2 \mathrm{~cm}^{3} \mathrm{~min}^{-1}$. The detector temperature was $340{ }^{\circ} \mathrm{C}$, and nitrogen was used as the make-up gas at a flow rate of $60 \mathrm{~cm}^{3} \mathrm{~min}^{-1}$. The injection volume was $2 \mu \mathrm{L}$. To investigate linearity 15 -point calibration curves were created.

\section{Statistical analysis}

The detection limits of the method were calculated by use of the formula:

$L O D=\frac{3.3 \times s}{b}$

where $s$ is the standard deviation of the calibration curve and intercept and $b$ is the slope of the calibration curve [16]. LOD was calculated as the mean of results obtained from the standard deviation of the calibration curve and intercept. Calculations were performed on the basis of a three-point curve (six injections for each point). The LOD was considered valid if:

$$
10 \times \mathrm{LOD}>C_{\min }
$$

and

$\mathrm{LOD}<C_{\min }$

where $C_{\min }$ is the concentration of the analyte in the standard solution of the lowest analyte concentration. Method quantitation limits were calculated by use of the formula:

$L O Q=3 \times L O D$

The sensitivity to each analyte was expressed as the slope of the calibration curve. Repeatability was expressed 
as the coefficient of variation for $n=7$, calculated by use of the formula:

$C V=\frac{S D}{\bar{X}} \times 100 \%$

where SD is the standard deviation of the peak areas obtained from analysis of six standard solutions, and $\bar{X}$ is the mean peak area. To establish linearity, the response values were divided by the analyte concentration. If the function of the resulting "relative responses" vs. concentration was constant, linearity was assured [17].

Real sample collection

Real samples were collected in duplicate from the water streams of a crude oil refinery. Wherever possible, samples were collected from valves; in other cases, samples were collected with a sampler. Glass samplers were filled with sample without a headspace, to prevent analyte losses. Samples were transported to the laboratory in a portable refrigerator, stored at $4{ }^{\circ} \mathrm{C}$ and analysed within $30 \mathrm{~h}$ at the latest [18].

$\mathrm{QA} / \mathrm{QC}$

Samplers were washed with detergent, then several times with ultrapure water (Milli-Q; Millipore, France) and methanol (Merck, Germany), after which they were dried overnight at $100{ }^{\circ} \mathrm{C}$ to remove any remaining traces of volatiles. The microsyringe (Hamilton, Switzerland) was washed with methanol before each analysis. To detect any possible contamination of the syringe and chromatographic system, blank samples were run after every seven real samples.

\section{Results and discussion}

The chromatographic procedure was developed. Figure 1 shows a chromatogram obtained from analysis of the standard mixture. Water elutes as a broad peak between 1.8

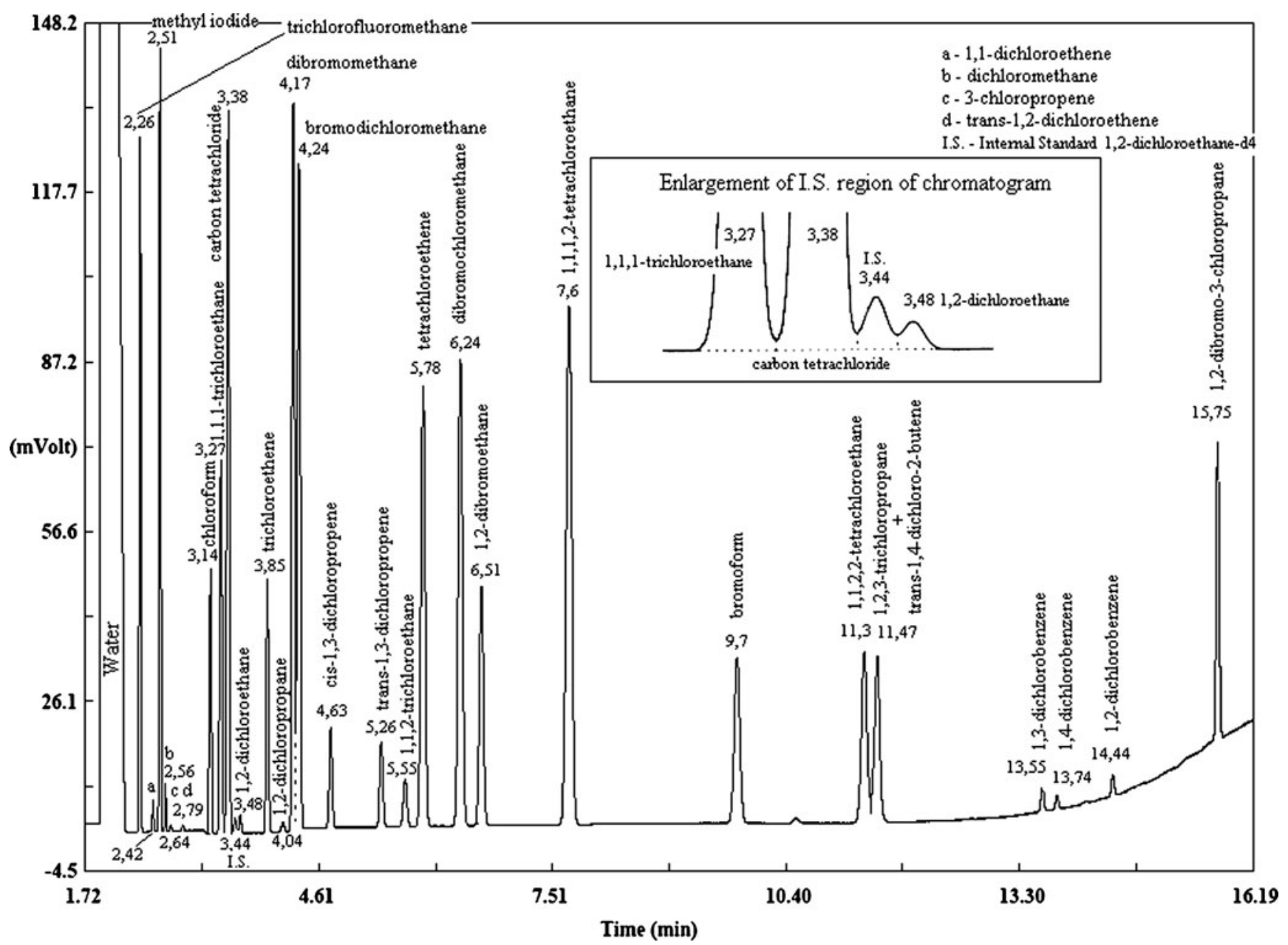

Fig. 1 Chromatogram obtained from analysis of a mixture of standards in ultrapure water 
and $2.05 \mathrm{~min}$. The analyte with the highest retention time elutes after $16.19 \mathrm{~min}$, after which the column is heated for $5 \mathrm{~min}$ at $200{ }^{\circ} \mathrm{C}$ to remove semi-volatile organic impurities. The priority analytes (dichloromethane, 1,2-dichloroethane, trihalomethanes, tetrachloroethene and trichloroethene) are well separated. 1,2,3-trichloropropane (b.p. $156{ }^{\circ} \mathrm{C}$ ) and trans-1,4-dichloro-2-butene (b.p. $155{ }^{\circ} \mathrm{C}$ ) are unresolved. The internal standard elutes at $3.44 \mathrm{~min}$ and is resolved from 1,2-dichloroethane.

Analytical features of the method

The sensitivity (Table 1) of the electron-capture detector depends on the structure of the analyte molecule: it is greater for compounds containing more halogen atoms and is also better for brominated compounds than for their chlorinated counterparts. The ECD is the most highly sensitive to methyl iodide, owing to the "hypercoulometric" properties of its molecules. Several electrons are consumed by a single methyl iodide molecule [19].
Limits of detection range from $0.03 \mu \mathrm{g} \mathrm{L}^{-1}$ for methyl iodide to $5.2 \mu \mathrm{g} \mathrm{L}^{-1}$ for 1,1-dichloroethane. The high sensitivity of the electron-capture detector toward halogenated compounds enables relatively low detection limits to be obtained without the need for analyte preconcentration. The upper linearity limits of the detector's response are higher for compounds with lower sensitivity. The repeatability achieved was good for most of the analytes, but was poor for dichlorobenzenes, 1,1-dichloroethene, 1,2-dichloropropane, and 1,1,2-trichloroethane.

\section{Matrix effects}

Matrix effects were investigated by spiking a sample with each analyte to obtain a $50 \mu \mathrm{g} \mathrm{L}{ }^{-1}$ solution. The oil content (measured according to EPA method 1664: Oil and Grease) in oily samples was below $10 \mathrm{gL}^{-1}$, the $\mathrm{pH}$ was $5-6$, and specific conductivity was $1-1.3 \mathrm{mS} \mathrm{cm} \mathrm{cm}^{-1}$. The detector responses are listed in Table 2. Normalization was performed by dividing the mean and standard deviation of

Table 1 Metrological data for every analyte

\begin{tabular}{|c|c|c|c|c|c|c|}
\hline Analyte & $\begin{array}{l}\mathrm{LOD} \\
\left(\mu \mathrm{g} \mathrm{L}^{-1}\right)\end{array}$ & $\begin{array}{l}\text { LOQ } \\
\left(\mu \mathrm{g} \mathrm{L}^{-1}\right)\end{array}$ & $\begin{array}{l}\text { Upper limit of linearity } \\
\left(\mu \mathrm{g} \mathrm{L}^{-1}\right)\end{array}$ & $r^{2}$ & $b$ & $\begin{array}{l}\mathrm{CV}(\%) \text { for } 1 \mu \mathrm{g} \mathrm{L}^{-1} \\
\left(* 20 \mu \mathrm{g} \mathrm{L}^{-1}\right)\end{array}$ \\
\hline Trichlorofluoromethane & 0.08 & 0.24 & 100 & 0.9862 & 46006 & 3.6 \\
\hline 1,1-Dichloroethene & 0.26 & 0.78 & 200 & 0.9819 & 3970 & 8.1 \\
\hline Methyl iodide & 0.03 & 0.09 & 100 & 0.9910 & 52284 & 3.1 \\
\hline Dichloromethane & 0.6 & 1.8 & 200 & 0.9972 & 943 & $1.8^{*}$ \\
\hline 1,1-Dichloroethane & 5.2 & 15.6 & 200 & 0.9296 & 422 & $4.3^{*}$ \\
\hline Chloroform & 0.05 & 0.15 & 100 & 0.9988 & 25434 & 3.3 \\
\hline 1,1,1-Trichloroethane & 0.043 & 0.129 & 100 & 0.9985 & 57932 & 3.8 \\
\hline Carbon tetrachloride & 0.07 & 0.21 & 100 & 0.9962 & 97377 & 4.1 \\
\hline 1,2-Dichloroethane & 0.33 & 1 & 200 & 0.9987 & 1615 & 3.9 \\
\hline Trichloroethene & 0.036 & 0.108 & 100 & 0.9962 & 41623 & 3.8 \\
\hline 1,2-Dichloropropane & 1.4 & 4.2 & 200 & 0.9961 & 1466 & $12 *$ \\
\hline Dibromomethane & 0.035 & 0.1 & 100 & 0.9910 & 68258 & 1.8 \\
\hline Bromodichloromethane & 0.014 & 0.042 & 100 & 0.9924 & 74217 & 3 \\
\hline cis-1,3-Dichloropropene & 0.15 & 0.45 & 200 & 0.9951 & 12720 & 3.7 \\
\hline trans-1,3-Dichloropropene & 0.16 & 0.48 & 200 & 0.9983 & 11708 & 3.7 \\
\hline 1,1,2-Trichloroethane & 0.15 & 0.45 & 200 & 0.9996 & 7740 & 6.4 \\
\hline Tetrachloroethene & 0.024 & 0.072 & 100 & 0.9988 & 114524 & 3.7 \\
\hline Dibromochloromethane & 0.025 & 0.075 & 100 & 0.9969 & 76496 & 1.6 \\
\hline 1,2-Dibromoethane & 0.05 & 0.15 & 100 & 0.9979 & 37825 & 3.9 \\
\hline 1,1,1,2-Tetrachloroethane & 0.028 & 0.084 & 100 & 0.9966 & 123321 & 1.8 \\
\hline Bromoform & 0.04 & 0.12 & 100 & 0.9994 & 37074 & 1.7 \\
\hline 1,1,2,2-Tetrachloroethane & 0.14 & 0.42 & 100 & 0.9998 & 38822 & 6.4 \\
\hline 1,3-Dichlorobenzene & 3.53 & 10.6 & 200 & 0.9929 & 3704 & $6.8^{*}$ \\
\hline 1,4-Dichlorobenzene & 3.9 & 11.7 & 200 & 0.9956 & 1816 & $7.3^{*}$ \\
\hline 1,2-Dichlorobenzene & 2.7 & 8.1 & 200 & 0.9982 & 2748 & $5.8^{*}$ \\
\hline 1,2-Dibromo-3-chloropropane & 0.17 & 0.51 & 100 & 0.9960 & 28892 & 4.3 \\
\hline
\end{tabular}


Table 2 Normalised recoveries $(\%)$ - mean and standard deviation (S.D.) for analytes from different water matrices

\begin{tabular}{|c|c|c|c|c|c|c|c|c|}
\hline \multirow[t]{2}{*}{ Analyte } & \multicolumn{2}{|c|}{ Ultrapure water } & \multicolumn{2}{|c|}{ Cooling water } & \multicolumn{2}{|c|}{ Process water } & \multicolumn{2}{|c|}{ Oiled wastewater } \\
\hline & Mean & S.D. & Mean & S.D. & Mean & S.D. & Mean & S.D. \\
\hline Trichlorofluoromethane & 100 & 5.8 & 90 & 1.5 & 101 & 6.7 & 89.3 & 3.9 \\
\hline 1,1-Dichloroethene & 100 & 7.1 & 91.1 & 3.3 & 100.3 & 6.8 & 90.9 & 4 \\
\hline Methyl iodide & 100 & 2.7 & 97.1 & 4.9 & 100.4 & 3.1 & 84.7 & 4.9 \\
\hline 1,1-Dichloroethane & 100 & 6.5 & 94.3 & 13.6 & 102.3 & 7.9 & 82.8 & 3.8 \\
\hline Chloroform & 100 & 3.2 & 95.2 & 4.7 & 100.4 & 3.6 & 87.9 & 2.6 \\
\hline 1,1,1-Trichloroethane & 100 & 5.2 & 95.4 & 6.1 & 100.1 & 4.3 & 87.3 & 3.7 \\
\hline Carbon tetrachloride & 100 & 4.7 & 95.3 & 3.8 & 99.6 & 4.0 & 86.8 & 5.3 \\
\hline 1,2-Dichloropropane & 100 & 6 & 93.2 & 4.2 & 85.4 & 5.9 & 76.4 & 3.3 \\
\hline Dibromomethane & 100 & 2.3 & 95.3 & 1.6 & 98 & 2.6 & 77.3 & 0.8 \\
\hline Bromodichloromethane & 100 & 1.9 & 96.5 & 3 & 99.6 & 2.9 & 73.4 & 0.5 \\
\hline cis-1,3-Dichloropropene & 100 & 2.4 & 95.2 & 3.1 & 100.7 & 5.3 & 67.5 & 3.2 \\
\hline trans-1,3-Dichloropropene & 100 & 2.9 & 94.5 & 1.5 & 100.6 & 4 & 70.5 & 2.9 \\
\hline 1,1,2-Trichloroethane & 100 & 3.3 & 94.7 & 1.3 & 99.9 & 4.3 & 75.6 & 3.1 \\
\hline Tetrachloroethene & 100 & 5 & 98.2 & 7.5 & 100.2 & 4.4 & 70.2 & 6 \\
\hline Dibromochloromethane & 100 & 2.7 & 95.9 & 2.1 & 99.6 & 3.5 & 76.6 & 1.6 \\
\hline 1,2-Dibromoethane & 100 & 3.4 & 94.9 & 1.6 & 99.9 & 2.8 & 81.4 & 1.8 \\
\hline 1,1,1,2-Tetrachloroethane & 100 & 2.2 & 99 & 5.2 & 99.7 & 3 & 77.3 & 2.9 \\
\hline Bromoform & 100 & 3.6 & 97.9 & 4.3 & 99.1 & 3.4 & 77 & 1.4 \\
\hline 1,1,2,2-Tetrachloroethane & 100 & 5.9 & 101.9 & 4.7 & 100.8 & 4.2 & 75.3 & 3.5 \\
\hline 1,3-Dichlorobenzene & 100 & 2.1 & 104 & 9.6 & 99.5 & 4.6 & 66.9 & 15.3 \\
\hline 1,4-Dichlorobenzene & 100 & 14.5 & 114.9 & 17.4 & 106 & 11.8 & 83.5 & 20.6 \\
\hline 1,2-Dichlorobenzene & 100 & 15.1 & 97.4 & 11.5 & 96.2 & 8.7 & 72.9 & 13.5 \\
\hline 1,2-Dibromo-3-chloropropane & 100 & 4.6 & 98 & 3.4 & 99.5 & 3.1 & 87.3 & 2.1 \\
\hline
\end{tabular}

the detector response by the mean detector response obtained from analysis of the standard mixture prepared in ultrapure water. Five injections were done to calculate the standard deviation. The results show that the process water matrix does not give significantly different results from ultrapure water. For most analytes in the cooling water matrix there is also no significant difference in detector response compared with ultrapure water. The detector's responses to analytes in oil-contaminated wastewater are significantly lower. This is because of partitioning of analytes between the two phases, so an internal standard quantification method must be applied. Deuterated 1,2dichloroethane is attractive as an internal standard for compounds eluting close to $3.44 \mathrm{~min}$ or as a surrogate compound, as it may not be present in real samples. Separation of deuterated compounds from the protonated forms is possible owing to the "inverse isotopic effect" observed in gas-liquid chromatography [20]. The isotopic effect is inverse when compounds containing heavier isotopes have greater vapour pressure. This is explained by shorter bonds formed by heavier isotopes and slightly lower molar volumes. The vapour pressure and, therefore, retention time is determined by the shape and the size of the molecule not the molar mass. Dichloroethane has four hydrogen atoms that can be substituted with deuterium atoms; this is sufficient to enable resolution of the deuterated and protonated forms of dichloroethane.

Comparison with other analytical methods

Table 3 compares metrological data with those for other techniques, for chloroform, 1,2-dichloroethane, and tetrachloroethene chosen as examples. Coefficients of variance were similar to those obtained with other techniques, and LODs for chloroform and tetrachloroethene (highly chlorinated compounds) were as low as for other techniques or one order of magnitude lower. The detection limit for 1,2dichloroethane is high compared with other methods. For DAI-GC-MS the detection limit for this compound was a factor of three lower than that for DAI-GC-ECD, although the reported sample injection volume was five times larger.

Halogenated solvents can be found in refinery process water and wastewater in wide concentration ranges - up to $\mathrm{mg} \mathrm{L}^{-1}$ levels. At the same time the matrix composition is highly variable, not only where different water streams are concerned but also from hour to hour. Some wastewater streams contain oil fractions, which makes the samples difficult to analyse. The DAI technique is a practicable 
Table 3 Comparison of limits of detection and coefficients of variance of analytical procedures for determination of chloroform, 1,2-dichloroethane, and tetrachloroethene

\begin{tabular}{|c|c|c|c|c|c|c|}
\hline Analyte & Sample-preparation technique & Detection & Sample volume & $\operatorname{LOD}\left[\mu \mathrm{g} \mathrm{L}^{-1}\right]$ & $\mathrm{CV}[\%]$ & Ref \\
\hline \multirow[t]{8}{*}{ Chloroform } & DAI & ECD & $2 \mu \mathrm{L}$ & 0.05 & 3.3 & This work \\
\hline & DAI & MS & $10 \mu \mathrm{L}$ & 0.07 & 3.9 & [23] \\
\hline & LPME & $\mu \mathrm{ECD}$ & $20 \mathrm{~mL}$ & 0.2 & 2 & {$[24]$} \\
\hline & LPME & MS & $9 \mathrm{~mL}$ & 0.5 & 4.8 & {$[25]$} \\
\hline & SPME & MS & - & 0.078 & 11.8 & {$[26]$} \\
\hline & $\mathrm{P} \& \mathrm{~T}$ & MS & $10 \mathrm{~mL}$ & Low ng $\mathrm{L}^{-1}$ & $<10$ & {$[27]$} \\
\hline & HS & ECD & $8 \mathrm{~mL}$ & 0.1 & 5.8 & {$[28]$} \\
\hline & $\mathrm{P} \& \mathrm{~T}$ & MS & $15 \mathrm{~mL}$ & 0.02 & 4.2 & [29] \\
\hline \multirow[t]{4}{*}{ 1,2-Dichloroethane } & DAI & $\mathrm{ECD}$ & $2 \mu \mathrm{L}$ & 0.33 & 3.9 & This work \\
\hline & DAI & MS & $10 \mu \mathrm{L}$ & 0.11 & 7.6 & {$[23]$} \\
\hline & SPME & MS & - & 0.065 & 2.9 & {$[26]$} \\
\hline & $\mathrm{P} \& \mathrm{~T}$ & MS & $15 \mathrm{~mL}$ & 0.002 & 7.4 & [29] \\
\hline \multirow[t]{6}{*}{ Tetrachloroethene } & DAI & ECD & $2 \mu \mathrm{L}$ & 0.024 & 3.7 & This work \\
\hline & DAI & MS & $10 \mu \mathrm{L}$ & 0.2 & 10 & {$[23]$} \\
\hline & SPME & MS & - & 0.044 & 4.4 & {$[26]$} \\
\hline & P\&T & MS & $10 \mathrm{~mL}$ & Low ng $\mathrm{L}^{-1}$ & $<10$ & [27] \\
\hline & HS & $\mathrm{ECD}$ & $8 \mathrm{~mL}$ & 0.1 & 8.2 & {$[28]$} \\
\hline & P\&T & MS & $15 \mathrm{~mL}$ & 0.014 & 3.5 & [29] \\
\hline
\end{tabular}

LPME liquid phase microextraction, SPME solid phase microextraction, $P \& T$ purge and trap, $H S$ headspace analysis

choice because it is relatively robust to matrix effects, although recovery of the analytes from oil-contaminated samples was only $70-90 \%$ (peak areas for oil-contaminated samples were approximately 10 to $30 \%$ lower than those obtained from ultrapure water analysis). Techniques based on headspace analysis (headspace in dynamic or static mode, purge and trap) are more sensitive to matrix effects, because of the co-solvent effect, which reduces the ability of an analyte to be transferred to the gaseous phase [21]. As a result, the metrological data of the method deteriorate, or the analysis is impossible to perform. Column performance can suffer from direct injection of water, because of formation of inorganic deposits near column inlet and hydrolysis of the stationary phase [22]. To avoid performance deterioration because of formation of non-volatile deposits a pre-column was installed and its inlet was shortened by $5 \mathrm{~cm}$ every $50-60$ runs. No deterioration in column performance or detection because of injection of water was observed.

Real sample analysis

Real samples were collected during four campaigns from May to August 2010. They were collected at 19 sampling points, usually with samplers or directly from the stream. The results for the four sampling points are presented in Table 4. At some sampling points, e.g. raw surface water before chlorination or the discharge of biologically purified process wastewater, no halogenated solvents were detected. If the detector response was higher than for the highest calibration point, the sample was diluted with ultrapure water before analysis to bring it within the calibration range.

The water fraction of oil-contaminated samples was also analysed by means of DAI-GC-ECD. To prevent contamination of the injection port or column with oil, proper syringe handling is required (Fig. 2). First the microsyringe with its piston up is immersed in the sample with the tip of the needle in the water. A rapid thrust of the piston releases air from the syringe together with an oil droplet that might have been left at the tip of the needle. The remaining air bubbles should be removed from the syringe by repeating this operation. A full volume of water is then taken from the sample with the syringe; any oil sticking to the outer part of needle is removed with filter paper, and excess water is removed from the syringe. The desired amount of water sample is injected into the GC column. After cleaning the microsyringe with methanol, the "wall-memory effect" was checked by analysis of ultrapure water: no syringe contamination was found to have occurred.

\section{Conclusions}

DAI-GC-ECD is a rapid, accurate and easily performed method for determining halogenated solvents in water samples. The method enables a range of halogenated 
Table 4 Selected results from analysis of real samples

\begin{tabular}{|c|c|c|c|c|c|}
\hline & Campaign & $\begin{array}{l}\text { Dichloromethane } \\
\left(\mu \mathrm{g} \mathrm{L}^{-1}\right)\end{array}$ & $\begin{array}{l}\text { Chloroform } \\
\left(\mu \mathrm{g} \mathrm{L}^{-1}\right)\end{array}$ & $\begin{array}{l}\text { 1,2-Dichloroethane } \\
\left(\mu \mathrm{g} \mathrm{L}^{-1}\right)\end{array}$ & $\begin{array}{l}\text { Tetrachloroethene } \\
\left(\mu \mathrm{g} \mathrm{L}^{-1}\right)\end{array}$ \\
\hline \multirow[t]{4}{*}{ Process water } & 1 & $(20.9 \pm 4.2) \times 10^{2}$ & $<\mathrm{LOD}$ & $1693 \pm 48$ & $<\mathrm{LOD}$ \\
\hline & 2 & $1149 \pm 67$ & $<\mathrm{LOD}$ & $(21.4 \pm 1.8) \times 10^{2}$ & $<\mathrm{LOD}$ \\
\hline & 3 & $1532 \pm 33$ & $<\mathrm{LOD}$ & $(30.4 \pm 1.2) \times 10^{2}$ & $<\mathrm{LOD}$ \\
\hline & 4 & $6.2 \pm 2$ & $<\mathrm{LOD}$ & $80.2 \pm 8.6$ & $<\mathrm{LOD}$ \\
\hline \multirow[t]{4}{*}{ Cooling water } & 1 & $<\mathrm{LOD}$ & $2.18 \pm 0.51$ & $<\mathrm{LOD}$ & $<\mathrm{LOD}$ \\
\hline & 2 & $<\mathrm{LOD}$ & $4.30 \pm 0.57$ & $<\mathrm{LOD}$ & $<\mathrm{LOD}$ \\
\hline & 3 & $<\mathrm{LOD}$ & $<\mathrm{LOQ}$ & $<\mathrm{LOD}$ & $<$ LOD \\
\hline & 4 & $<$ LOD & $<\mathrm{LOQ}$ & $<$ LOD & $<$ LOD \\
\hline \multirow{4}{*}{$\begin{array}{l}\text { Oiled process wastewater influent } \\
\text { to treatment plant }\end{array}$} & 1 & $88.8 \pm 7.2$ & $<\mathrm{LOD}$ & $140 \pm 10$ & $0.115 \pm 0.029$ \\
\hline & 2 & $23.5 \pm 1.3$ & $<\mathrm{LOD}$ & $61.1 \pm 4.2$ & $5.05 \pm 0.21$ \\
\hline & 3 & $21.6 \pm 1.2$ & $<\mathrm{LOD}$ & $94.2 \pm 4.8$ & $0.369 \pm 0.017$ \\
\hline & 4 & $1.91 \pm 0.29$ & $<$ LOQ & $51.6 \pm 5.1$ & $4.24 \pm 0.4$ \\
\hline \multirow{4}{*}{$\begin{array}{l}\text { Runoff water influent to treatment } \\
\text { plant }\end{array}$} & 1 & $263 \pm 18$ & $0.69 \pm 0.25$ & $497 \pm 24$ & $0.716 \pm 0.077$ \\
\hline & 2 & $131.5 \pm 8.9$ & $0.43 \pm 0.12$ & $227 \pm 19$ & $0.69 \pm 0.16$ \\
\hline & 3 & $38.5 \pm 1.8$ & $0.70 \pm 0.33$ & $56.4 \pm 2.8$ & $<\mathrm{LOQ}$ \\
\hline & 4 & $77 \pm 17$ & $<\mathrm{LOQ}$ & $189 \pm 19$ & $4.93 \pm 0.97$ \\
\hline
\end{tabular}

$<L O D$ below detection limit, $<L O Q$ detected but not quantified

solvents that could be present in industrial water and wastewater to be determined. Obtaining an analytical result in a short period of time is crucial for ensuring chemical engineering safety. The method is relatively unsusceptible to matrix effects. 1,2-Dichloroethane- $\mathrm{d}_{4}$ was applied as internal standard and surrogate compound in electroncapture detection. The limits of detections were at low or sub- $\mu \mathrm{g} \mathrm{L}^{-1}$ levels, and precision for most analytes was below 5\%. DAI-GC-ECD was successfully used to determine halogenated solvents in refinery water streams.
Fig. 2 Procedure for sampling oil-contaminated water
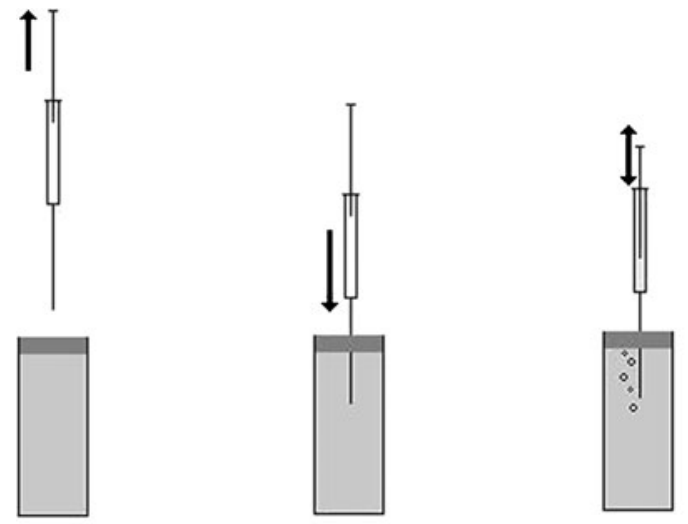

Oil

Water

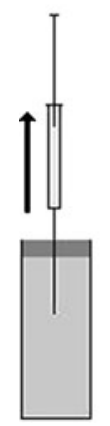

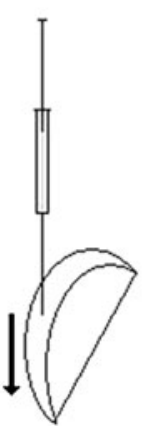

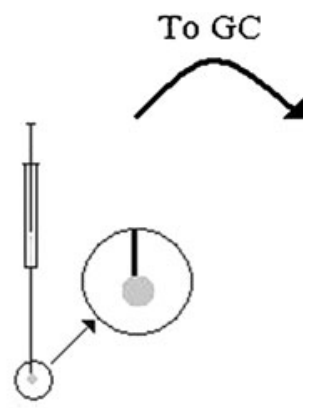


Acknowledgments The authors would like to thank refinery workers for their kind help with sample collection and the Foundation for Polish Science for financial support from the MISTRZ Programme. M. Tobiszewski expresses his gratitude for financial support received from the Human Capital Programme (POKL.04.01.01-00-368/09) and for financial support in the form of a grant awarded by the Polish Ministry of Science and Higher Education (NN 523 562838).

Open Access This article is distributed under the terms of the Creative Commons Attribution Noncommercial License which permits any noncommercial use, distribution, and reproduction in any medium, provided the original author(s) and source are credited.

\section{References}

1. Juang DF, Lee CH, Hsueh SC (2004) Chlorinated volatile organic compounds found near the water surface of heavily polluted rivers. Int J Environ Sci Tech 6:5-556

2. Chen G (2004) Reductive dehalogenation of tetrachloroethylene by microorganisms: current knowledge and application strategies. Appl Microbiol Biotechnol 63:373-377

3. Bagajewicz M (2000) A review of recent design procedures for water networks in refineries and process plants. Comp Chem Eng 24:2093-2113

4. Nikolaou AD, Lekkas TD, Golfinopoulos SK (2004) Kinetics of the formation and decomposition of chlorination by-products in surface waters. Chem Eng J 100:139-148

5. Pérez Pavón JL, Martín SH, Pinto CG, Cordero BM (2008) Determination of trihalomethanes in water samples: a review. Anal Chim Acta 629:6-23

6. Henderson JK, Falta RW, Freedman DL (2009) Simulation of the effect of remediation on EDB and 1,2-DCA plumes at sites contaminated by leaded gasoline. J Contam Hydrol 108:29-45

7. Jin S, Fallgren PH, Morris JM, Edg ES (2008) Degradation of trichloroethene in water by electron supplementation. Chem Eng J 140:642-645

8. Golfinopoulos SK, Lekkas TD, Nikolaou AD (2001) Comparison of methods for determination of volatile organic compounds in drinking water. Chemosphere 45:275-284

9. Hong S, Duttweiler CM, Lemley AT (1999) Analysis of methyl tert.-butyl ether and its degradation products by direct aqueous injection onto gas chromatography with mass spectrometry or flame ionization detection systems. J Chromatogr A 857:205-216

10. Pyle SM, Marcus AB (2000) Analysis of volatiles and semivolatiles by direct aqueous injection. Int J Environ Anal Chem 76:17-29

11. Pyle SM, Gurka DF (1994) Volatile organic analysis by direct aqueous injection. Talanta 41:1845-1852

12. Tobiszewski M, Mechlińska A, Zygmunt B, Namieśnik J (2009) Green analytical chemistry in sample preparation for determination of trace organic pollutants. Trends Anal Chem 28:943-951

13. Wolska L, Olszewska C, Turska M, Zygmunt B, Namieśnik J (1998) Volatile and Semivolatile organo-halogen trace analysis in surface water by direct aqueous injection GC-ECD. Chemosphere $37: 2645-2651$
14. Polkowska Ż (2004) Determination of volatile organohalogen compounds in urban precipitation in Tricity area (Gdańsk, Gdynia, Sopot). Chemosphere 57:1265-1274

15. Wortberg M, Ziemer W, Kugel M, Muller H, Neu HJ (2006) Monitoring industrial wastewater by online GC-MS with direct aqueous injection. Anal Bioanal Chem 384:1113-1122

16. Konieczka P, Namieśnik J (2009) Quality assurance and quality control in the analytical chemical laboratory: a practical approach. CRC Press/Francis and Taylor, Boca Raton

17. Taverniers I, De Loose M, Van Bockstaele E (2004) Trends in quality in the analytical laboratory. II. Analytical method validation and quality assurance. Trends Anal Chem 23:535-552

18. Kozłowska K, Polkowska Ż, Przyjazny A, Namieśnik J (2006) Investigation of stability of aqueous solutions containing trace amounts of volatile organic analytes. Trends Anal Chem 25:609-620

19. Grimsrud EP, Knighton WB (1982) Response of electron capture detector to methyl iodide. Anal Chem 54:565-570

20. Matucha M, Jockish W, Verner P, Anders G (1991) Isotope effect in gas-liquid chromatography of labeled compounds. J Chromatogr A 588:251-258

21. Allonier AS, Khalanski M, Bermond A, Camel V (2000) Determination of trihalomethanes in chlorinated sea water samples using a purge-and-trap system coupled to gas chromatography. Talanta 51:467-477

22. Grob K (1984) Further development of direct aqueous injection with electron-capture detection in gas chromatography. J Chromatogr 299:1-11

23. Aeppli C, Berg M, Hofstetter TB, Kipfer R, Schwarzenbach RP (2008) Simultaneous quantification of polar and non-polar volatile organic compounds in water samples by direct aqueous injectiongas chromatography/mass spectrometry. J Chromatogr A 1181:116-124

24. Vora-adisak N, Varanusupakul P (2006) A simple supported liquid hollow fiber membrane microextraction for sample preparation of trihalomethanes in water samples. J Chromatogr A 1121:236-241

25. Aguilera-Herrador E, Lucena R, Cárdenas S, Valcárcel M (2008) Determination of trihalomethanes in waters by ionic liquid-based single drop microextraction/gas chromatographic/mass spectrometry. J Chromatogr A 1209:76-82

26. Niri VH, Bragg L, Pawliszyn J (2008) Fast analysis of volatile organic compounds and disinfection by-products in drinking water using solid-phase microextraction-gas chromatography/time-offlight mass spectrometry. J Chromatogr A 1201:222-227

27. Zoccolillo L, Amendola L, Cafaro C, Insogna S (2005) Improved analysis of volatile halogenated hydrocarbons in water by purgeand-trap with gas chromatography and mass spectrometric detection. J Chromatogr A 1077:181-187

28. Kuivinen J, Johnsson H (1999) Determination of trihalomethanes and some chlorinated solvents in drinking water by headspace technique with capillary column gas-chromatography. Water Res 33:1201-1208

29. Martıneza E, Lacortea S, Llobeta I, Vianab P, Barcelo D (2002) Multicomponent analysis of volatile organic compounds in water by automated purge and trap coupled to gas chromatographymass spectrometry. J Chromatogr A 959:181-190 